\title{
Chapter 12 \\ Toward Transformation to a Well-Being Economy in an African Country: A Case Study from Namibia
}

\author{
Justine Braby and Reinhold Mangundu
}

\begin{abstract}
In this chapter presents the results of various approaches used by a group of young Namibians to shift the society toward a well-being economy. They sought to find more appropriate measurements of success, and did this by conducting (a) a survey to measure progress, (b) different dialog processes to understand what a good quality of life actually means to citizens, (c) co-constructing community well-being from the bottom up, (d) communication, networking, and awareness to garner public support, and finally (e) attempting to influence high-level decisionmaking in government. The authors measured nine domains; of which, state of mind and perceived health were the only domains found to be sufficient. The domains community strength and sense of belonging were the lowest in the high-income area. The domains with the highest levels of dissatisfaction were good governance and political freedom. The process of co-constructing community well-being through a bottom-up approach had varying levels of success and was highly adaptive and flexible. The key findings were that the underlying components of well-being were trust (at all levels), a sense of belonging and healthy relationships, basic needs (home, food, water, sanitation, electricity), quality education (the kind that causes critical and systems thinking and develops creative potential), quality work (that is demanding and rewarding), and good health.
\end{abstract}

Keywords Wellbeing economy $\cdot$ Community $\cdot$ Systems thinking $\cdot$ Circular economy $\cdot$ Transformation $\cdot$ Namibia

\subsection{Introduction}

It has become widely recognized that our current global development path is not taking us in the right direction (Constanza et al., 2014; Rogers et al., 2012; Steffen et al., 2015; Stiglits et al., 2009; Whitby et al., 2014). Vast numbers of people live in poverty, and those countries that are deemed successful according to our economic paradigm have major health problems (Compas et al., 2012; Rogers et al., 2012),

J. Braby $\cdot$ R. Mangundu ( $\varangle)$

Progress Namibia, Windhoek, Namibia 
depression, and anxiety (Bromet et al., 2011; Streib, 2007). In addition, the globally dominant economic system dependent on industrialization is increasingly putting Earth, and its ecosystem, goods and services, under untenable pressure, which has direct effects on human wellbeing (Constanza et al., 2014; Stiglits et al., 2009).

It is important to consider that the point of economic growth is to drive equity and life quality, while making sure not to harm the natural systems on which our economy and life, in general, is based. However, the focus on growth alone without understanding and strategizing what kind of growth and for whom has resulted in the opposite in many countries. In most countries, in the world over the last 40 years, more than half of the wealth generated by economic growth has gone to the top $1 \%$, while the poorest half has received less than $1 \%$ of that growth in wealth (Hardoon et al., 2016). In Namibia, less than $10 \%$ earns more than NAD 11,000 per month, while more than $60 \%$ of Namibians earn less than NAD 2,000 per month (NSA 2011).

Economic growth, in itself, is neither good nor bad. It can range from really good (e.g., higher incomes and better health) to really bad (e.g., opioid addictions or armed conflict) - all of these are forms of economic growth. Polluted ground water means that the population is forced to buy more plastic bottled water. This has shown to contribute to further plastic pollution, and microplastics in our guts which can be harmful to our health-hence more spending on health care. This all contributes to growth, but it certainly does not make life better; in fact, it is detrimental. So, the central question becomes: what do we want to grow, and why?

Namibia is a developing country with the driest climate in sub-Saharan Africa. Namibia's Vision 2030 is for the country to be industrialized by the year 2030 . However, it also states that this development must also be sustainable, and the ultimate direction is toward the well-being of Namibia's citizens (Republic of Namibia 2004). Namibia needs to develop. For growth to be a net positive in a country like Namibia, it needs to be (1) equitable, (2) clearly defined in terms of types and assumed benefits, and (3) environmentally and socially sustainable. Most vital development does not necessarily require growth, but rather depends on inclusivity, reciprocity, efficiency, and above all, quality.

In 2012, a group of young Namibians (including a myself-a sustainability professional, with a medical doctor, a physicist, a land use planner, a youth development expert, a social entrepreneur, and an engineer, hereafter referred to as the committee) embarked on a journey to question what progress means to ordinary citizens, what alternative indicator system could be used to measure this progress, and influence the decision-making processes around development and economic growth in the country. This work formed part of the For Progress Namibia Project (www.progress-namibia. com). This chapter narrates this journey and attempts to synthesize lessons learnt to improve approaches for further work in this area in Namibia, and other countries that want to embark on transformation toward a well-being economy. In his book titled Success in a World Without Growth, Fioramonti (2017) describes a "well-being economy" as one that seeks to uphold the well-being of both social and ecological systems without undermining them. At the core of this paradigm, people and the environment are equally valued as the two constitute an interdependent system. A 
well-being economy calls for a common narrative on what progress and a good life would mean to people. Progress does not necessarily mean material consumption but sees the need for things that truly matter. Some of these things do not have any monetary value but contribute greatly to our state of being, e.g., community trust, social cohesion, peace, and happiness (Fioramonti, 2017).

This chapter attempts to take a system's lenses and outlines various points of entry (or leverage points) in the system where the committee attempted to intervene. A survey was used to measure perceptions on progress, while several in depth dialogs and community working groups were established. Other interventions include communications and awareness to attempt to change mental models around progress, and finally, attempting to influence high-level decision-making. The ultimate aim of the project was to support and guide development in Namibia by looking at what is important for citizens to lead a good quality of life using the strengths and resources of Namibia and focusing on local decentralized economic development.

\subsection{Approaches to Shifting Namibian Society Toward a Well-Being Economy}

The attempts made to shift Namibian society toward a well-being economy were not strategic as the For Progress Namibia project learnt as it went along, taking an organic, flexible, adaptive approach. The project started in 2012, when a few young Namibians who were working on joint youth development projects at the time, came together to discuss progress and the inefficacy of the gross domestic product (GDP) as a measurement of progress. The results of this study, starting with a survey, as well as the work of some of the members of the committee, resulted in a multi-faceted approach to transformation in Namibia (to ultimately varying, and in some cases, very limited, success).

The approach and methodology are discussed in more detail under the subheadings below. The project started through the formation of the For Progress Namibia Committee (the committee), basically a group of volunteers who all shared a passion for their country and its citizens' well-being. Its main initial aim was to find more appropriate measurements of success, and it did this by conducting (a) a survey to measure progress, (b) conduct and test different dialog processes to understand what a good quality of life actually means to citizens, (c) co-constructing community well-being from the bottom up, (d) communication, networking and awareness to garner public support, and finally (e) attempting to influence high-level decisionmaking in government. Excluding the survey which was done at the onset, all these approaches were ongoing and sometimes done at the same time, between 2012 - and continue today. It is important to note that in retrospect the project made mistakes, faced several challenges, and had a lot of mentorship and technical support along the way; as in reality, it was setting a trail that had not previously been undertaken in such a holistic manner by one group of people. 


\subsubsection{Survey to Measure Progress}

A literature review of the existing alternative indicators of welfare and well-being globally was conducted as well as the use and advisory support from various experts in the field. Perception indicators were chosen using the approach of Bhutan's Happiness Index ${ }^{1}$ and the Happiness Alliance. ${ }^{2}$ A questionnaire was developed using these foundations. The survey was conducted in the capital city of Namibia, Windhoek, in four suburbs of different income levels: Ludwigsdorf (high income), Windhoek West (middle income), Shandumbala (low-middle income), Okuryangava (low income), Hakahana (low income). Volunteers were trained to conduct the surveys, and surveys were conducted between August and October 2012. Approximately, 600 people were surveyed in total, and suburban variation depended on various factors, such as willingness to answer, and number of surveyors.

\subsubsection{Interviews and Focus Group Discussions}

To better understand how we measure progress, the project embarked on using various dialog and depth facilitation processes to collect narratives on what Namibian citizens think progress means, a "good life" means, and what thriving society would look like.

The committee used the following different formats:

1. Interviews (mostly one-on-one) with citizens from different demographics

2. Community discussions using the Bohm dialog format (between 5 and 20 people)

3. Using gaming and simulations followed by depth dialogs (creating a safe space using different depth dialog processes) (see Mangundu \& Braby, 2019)

4. Co-creating (e.g., community gardens, cooking together in someone's home) and having informal discussions

5. Community visioning exercises in a workshop format (groups were put together to draw their ideal neighborhood)

\subsubsection{Co-Constructing Community Well-Being Bottom up}

As part of the survey study, the committee identified a community/suburb of the four survey suburbs in Windhoek to work with to (a) present the findings and results of the survey and (b) co-identify and work on priority areas that could improve sufficiency. Because of the committee's existing community involvement and residency, Shandumbala was chosen. The work of this was conducted in the following manner:

\footnotetext{
${ }^{1}$ (www.grossnationalhappiness.com).

2 (www.happycounts.org).
} 
1. A Shandumbala Community Workshop was held in 2016 where results were presented and where community visioning was conducted. Here, central government was invited to attend (of six Ministries invited, only two attended, namely from the National Planning Commission, and one Member of Parliament). Local Government was invited, including the Mayor of the City of Windhoek (who seconded some staff to join) and the Katutura East Constituency Councilor at the time. In addition, some NGOs and International Development Partners were invited, of which most notably the UNDP Resident Representative of Namibia attended. Approximately, 50 residents attended and together worked on visioning what their ideal suburb would look like in 2036 (20 years from time of workshop).

2. A community meeting followed a month after (2016), hosted by the Katutura East Councilor who had requested the committee to include the entire constituency (several suburbs of which Shandumbala was only one suburb). At this meeting, over 100 people were attended (Fig. 12.1). A prioritization exercise was conducted in which four components were identified as priority areas that the community wanted to focus on and improve (see Fig. 12.2). These were (a) community trust, (b) safety, (c) education, and (d) land rights at an informal settlement called Sonderwater. People were asked to sign up to be part of "task teams" to work on individual areas. Each area had approximately ten task team members, including one person from the committee.

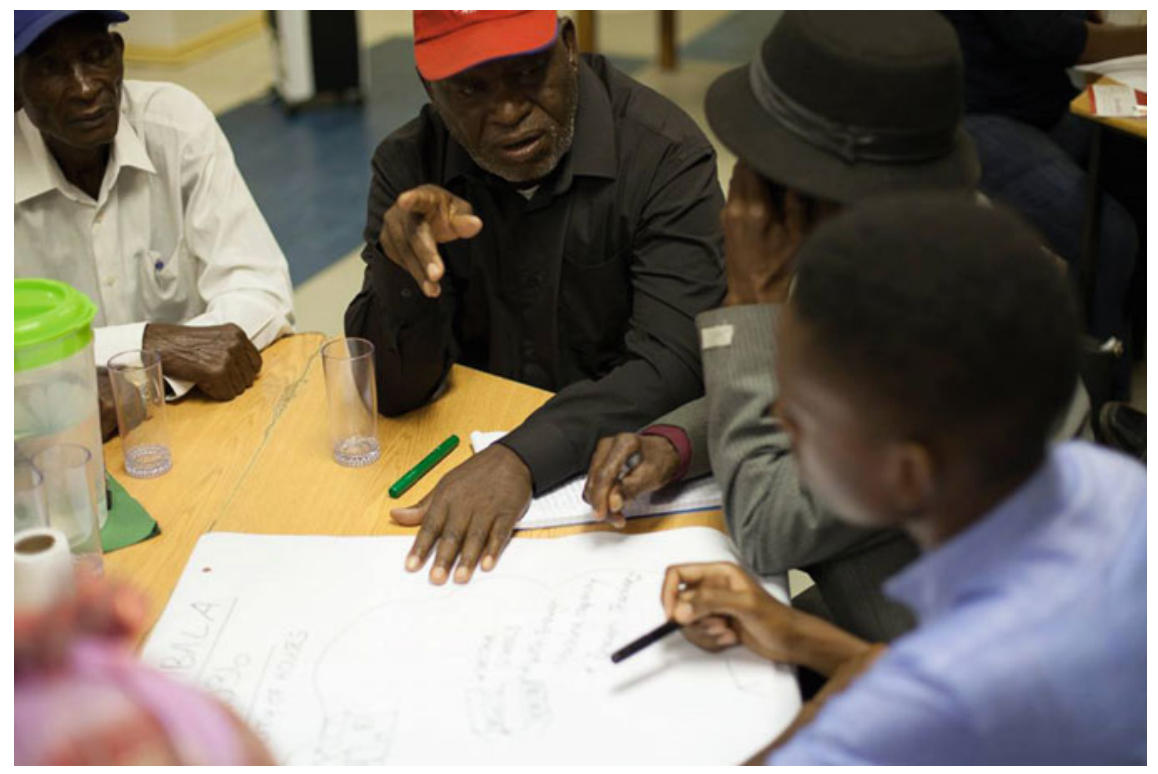

Fig. 12.1 Residents of Katutura east constituency partaking in an envisioning exercise (Van Schalkwyk, 2016) 
Fig. 12.2 Elder from Sonderwater community prioritizing land rights (Van Schalkwyk, 2016)

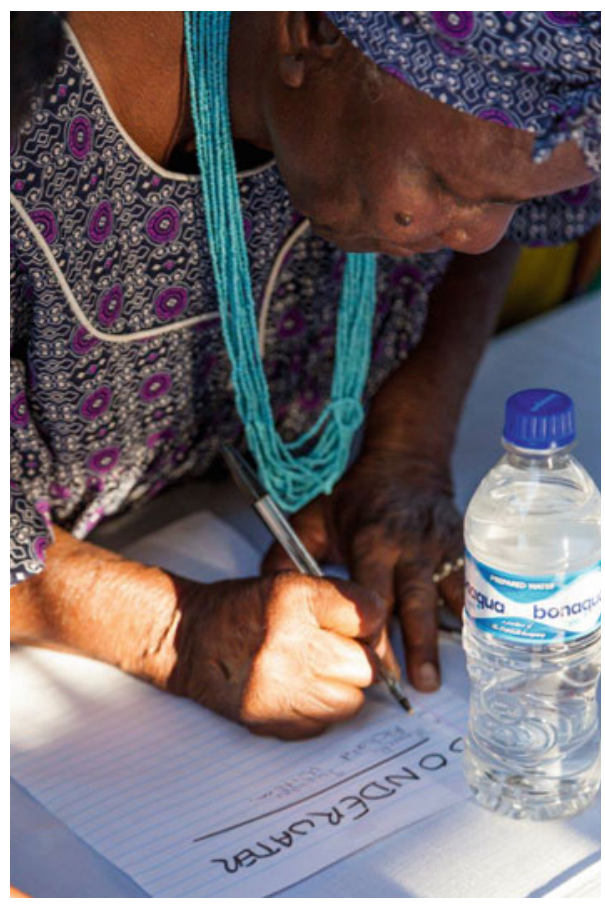

3. For the "trust task team" community dialogs were hosted with minimal success. This was mainly due to internal personality clashes between some members of the trust team consisting of community members which could not be solved through committee facilitation. These are discussed below as part of the overall reflection of this process.

4. For the "safety task team," it was decided to set up a neighborhood watch, which included a successful partnership with the Police. This neighborhood watch is still ongoing in 2020 and has been successful in limiting crime in Katutura East.

5. The "education task team" initiated with letters to the Ministry of Education in support of improving school conditions in Katutura East (to minimal success), the use of the councilor building for matric students to have a quiet place to study, and the partnership with the Physically Active Youth (with whom the Committee had a long-standing relationship with) who provide a safe, homestyle setting to school children in the afternoons to supplement education that is lacking in the formal school system.

6. The "Sonderwater task team" has been the most active, mostly due to strong leadership from one community member in Sonderwater, as well as active and engaged facilitation from one committee member. Sonderwater is an informal settlement of 150 residents who live in informal housing (tin shacks/plastic shacks) without tenure to land or access to sanitation or power. The work here 
started with meetings with the City of Windhoek which allowed for the "formalization" of the suburb (which meant a stop to the forceful removal of residents there) and the installation of water, so residents have access to water. In addition, a local economic development project was started using carpentry as a medium. The task team partnered with a carpentry training center, and interested and engaged residents looking for employment were trained in carpentry using pallets to make furniture (see Fig. 12.3). After training, a small business/cooperative was formed where pallets (mostly from Coca Cola Namibia) were delivered for free and repurposed into furniture (an auction was held successfully). Demand grew and clients (like restaurants) made orders, raising the potential for the business to become successful. However, the lack of financial management expertise, lack of work ethic and rampant drug addiction in the community caused the failure of the business, leaving only a few individuals, continuing on their own. These individuals were supported with a container and tools set up within the Sonderwater area. In addition, in 2020, community gardens were developed by community members in a larger partnership which had rising success and is being used as a model in various platforms of food security and adaptation during the covid pandemic.
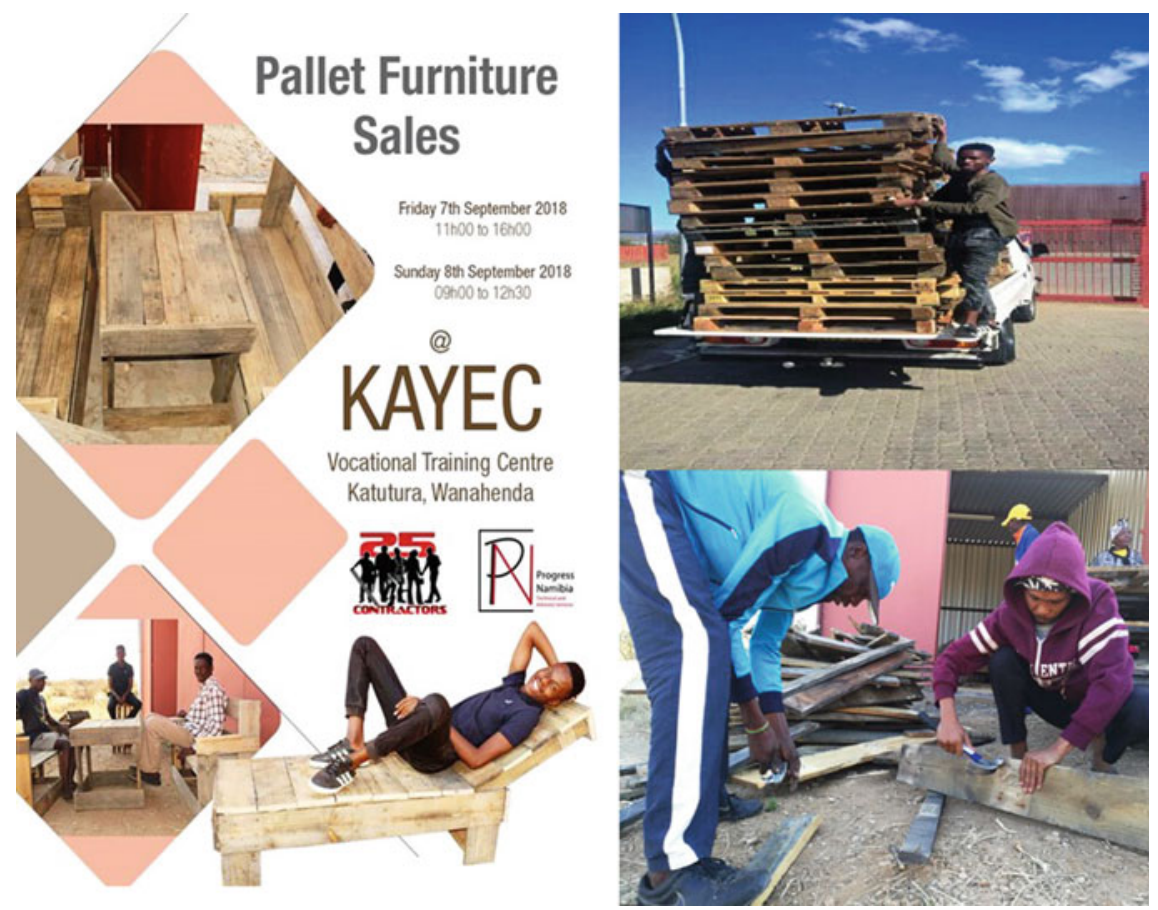

Fig. 12.3 Processes of the pallet project (Mangundu, 2018) 


\subsubsection{Communication, Networking and Awareness-Public Support}

The Progress Namibia Project was well aware of the influence that communication and awareness raising can make, especially when it came to influencing decisionmaking in Namibia. For this reason, a communications strategy was developed already at survey stage and was further adapted as the work progressed and moved into different avenues.

The following aspects were part of this "living" strategy:

1. Every event, paper published, meeting, or other news-worthy activity were put into a media advisory note and sent to all media houses (including newspapers, radio, and television) in Namibia (starting in 2012).

2. As a result of the above, members of the committee were frequently interviewed, and thus, various topics received multiple platforms, most notably and influentially, the Namibia Broadcasting Corporation's TV shows "Good Morning Namibia" (a news show), "One on One" (a debate show), and "Talk of the Nation" (a panel show discussing "hot topics"). Multiple radio interviews and newspaper articles were also done.

3. One of the committee members (the senior author) was invited to be part of the "WE-Africa Lab" (a think-tank of 28 participants across Africa developing strategies on a well-being economy for Africa) which included three lab sessions across Africa and resulted in the inclusion and ultimate Secretarial Leadership of the For Progress Namibia project in the well-being economy Africa Action Network. One of the more notable pieces of work (although not part of the For Progress Namibia Project) was the publication of a book entitled "Transformational Infrastructure: for Development of a Well-being Economy in Africa" (Mebratu \& Swilling, 2020).

4. A prominent figure and author on the well-being economy (Prof Lorenzo Fioramonti) was invited on a mission to Namibia. This included various TV and radio interviews, meetings with Ministers, and an extremely well-attended public talk co-organized with the Namibia Economic forum and the Pupkewitz Business School at the Namibia University of Science and Technology entitled "Real Economic Transformation in Africa: breaking free from growth and embracing well-being."3

5. Weekly blog news articles starting in 2017 called "Progress Namibia Weekly" mailed out to an automated list (which grew to several hundred) of emails, as well as published on the Progress Namibia Web site. ${ }^{4}$

6. Presentations at multiple meetings, conferences, including inter-alia, the wellbeing economy Africa Festival held in Pretoria in 2017, and the Resilience Conference held in Stockholm in 2017.

\footnotetext{
${ }^{3}$ The talk was filmed and made into a video (https://www.youtube.com/watch?v=BmDrRT K0jMA\&t=318s\&ab_channel=ProgressNamibia).

${ }^{4}$ See link to the Progress Namibia website (www.progress-namibia.com).
} 
A large majority of the influence at political and high level was due to the debate and public support garnered through the media's interest in this work. This is discussed below.

\subsubsection{Influencing High-Level Decision-Making}

It was always the intention of the For Progress Namibia project to influence highlevel decision-making in the development and economic planning arenas, and as a result, various strategies and activities were employed in this regard, including:

1. A policy brief was developed of the survey (Braby, 2016), which was handed to every member of Parliament, sent to every Minister in Cabinet, and used as the information brief on which meetings were held with various politicians.

2. Several meetings were held in 2016 to garner interest in the work with the Shandumbala community. This included (a) a meeting with the Chair of Parliament, (b) subsequent presentations and meetings with parliamentarian committees (see Fig. 12.2), (c) a meeting with the Mayor of the City of Windhoek. Letters were drafted and sent to every minister requesting a meeting (of which none responded).

3. During the visit of Lorenzo Fioramonti (2017), various meetings were held with UNDP, various bi-lateral organizations, as well as the Minister of the National Planning Commission (in charge of economic and development planning in Namibia) .

4. Eventually, toward the end of 2018, the Presidential Advisors (mostly due to the TV debate shows) contacted one of the committee members (the author) for meetings and advice. By 2019, the committee member was appointed to the High-Level Panel Advising the President of Namibia on the Economy. This appointment was from 2019 to 2020 and had limited to no success. The lack of success was due to the following factors: (a) while the appointment was done with the aim of the Presidential Advisors to support a more systemsthinking visioning of what development in Namibia should look like, the actual terms of reference was focused almost exclusively on growth and investment to trigger more growth in the short-to-medium term, (b) the panel had 22 seats of which most were neo-liberal economists, (c) the panel did not have a clear direction and instead focused on very short-term solutions, (d) there was a lack of transparency, (e) the composition of the panel (heads of banks, investment institutions, some with political aspirations) which included political appointees in an election year (i.e., pleasing certain constituencies) led to many alternative voices not being heard, (e) the committee member, despite having spent an enormous amount of effort in writing visions, blueprint strategies (including for energy, education, work, economic development), as well as various meetings with individual panelists, did not have the capacity to infiltrate the thinking of the panel leadership. The committee member requested to resign at various 
occasions, but this did not happen, also for various reasons. What resulted from this panel was very little, and during 2019/2020, a corruption scandal in the fishing industry (referred to as \#fishrot), the covid pandemic, further diluted any powers the panel had. Overall, the appointment of the committee member to the panel was perhaps "ahead of its time."

5. The running of one of the committee members in the local constituency elections (Constituency Councilor for Katutura East), while close, lost out to the dominant political party.

\subsection{Results}

This section presents the results obtained from the different approaches and the methodology applied by the For Progress Namibia Project, as presented in the previous section. The results from the survey showed an overall sufficiency (or, in layman terms "satisfaction rate") of $45.9 \%$. Generally, well-being seemed to correlate along the income line, with the exception of Okuyrangava. Of nine domains measured (state of mind; health; time balance; community strength; education, recreation and culture; area and environment; good governance and political freedom; material well-being; work), state of mind, and perceived health were the only domains found to be sufficient. Community strength and sense of belonging to a community are immensely important components - these were the lowest in the high-income area. The domain with the highest levels of dissatisfaction were good governance and political freedom. The detailed survey results and discussion can be found in Braby et al. (2016).

Through the interviews and focus group discussions carried out between 2012 and 2018, it was found that interviews specifically did not allow for deeper digging (this of course depended on the questioning format), but generally, respondents would answer very superficially, the type of answers that come from manipulation caused by advertising such as (e.g., "I want to have Nike shoes" "I want to drive a hummer" "I want to have a big house"); mental environmentalism looks at the counter-culture to advertising causing societal manipulation (e.g., see Menees 2014). This processes also confirmed some of the ideas outlined in Costanza et al. (2017) which outlines societal addiction to short-term rewards and addictions to over-consumption. Depth dialog processes, especially when respondents felt safe and trusting, managed to draw deeper and more reflective thoughts. ${ }^{5}$

The process of co-constructing community well-being through a bottom up approach had varying levels of success and was highly adaptive and flexible. Because the committee was small (five people) and funding was minimal, some activities had to be dropped. Some task teams suffered from leadership issues within the community (relationship issues between members, ego versus "good of community", inappropriate use of funds, etc.). Various issues with the councilor's office (including signs

\footnotetext{
${ }^{5}$ This short video publication was released showing some of the processes the committee took (https://www.youtube.com/watch?v=t7pkhDPhWK4\&ab_channel=ProgressNamibia).
} 
of corruption, sexism, and internal leadership issues) meant that the work was eventually done in partnership, but with minimal support from the office. More detailed outcomes were published in Braby et al. (2017).

Leadership, championship, and facilitation expertise, as well as engagement and partnership support had a lot of influence on the success of the community work. Because surveys were not conducted again, it is impossible to say with confidence whether sufficiency was improved in Shandumbala. However, it can be said that the community at Sonderwater has improved, including access and general livelihoodsbased on qualitative discussions. Notably, community championship was resulted from the best interests of community, good facilitation, and engagement from the committee members, as well as support and interest from outside.

The key findings from the qualitative collating of these narratives were that the key underlying components of a "content society" were (in no particular order) as follows: trust (at all levels), a sense of belonging and healthy relationships, basic needs (home, food, water, sanitation, electricity), quality education (the kind that causes critical and systems thinking and develops creative potential), quality work (that is demanding and rewarding), and good health. Above these, basic foundational components were perspectives and mental models, which varied from person to person.

The overall findings supported the development of a vision for a "thriving Namibia" which was presented by one of the committee members (the senior author of this chapter) who was appointed in 2019 by the President of Namibia to serve on the high-level panel on the economy (advising the President on "bold and practical solutions to arrest the triple challenge of unemployment, income inequalities, and poverty") (Braby, 2019).

\subsection{Conclusions}

Globally, continued economic growth is neither sustainable nor desirable, while countries like Namibia do have to grow (in terms of opportunities for our people, life quality, health, education, clean renewable energy, etc.), others will have to shrink (e.g., carbon emissions, resource depletion, plastic pollution, national debt, etc.).

However, Namibia still follows the mainstream growth development model. In 2019, the annual budget, while aiming to stimulate "growth" in key areas like infrastructure (instead of leap-frogging infrastructure, most budget went into roads and other infrastructure that will likely be obsolete in years to come), social safety nets (complicated and lots of red tape, instead of investment into a universal basic income which had been very successfully tested in the country), agriculture (mostly unsustainable), youth and SME support. However, the Ministry of Defense was allocated 6 billion NAD where youth entrepreneurship projects were allocated less than 50 million and SME development 110 million.

The work of For Progress Namibia Project could be potentially upscaled to other communities in Namibia. The communities supported by the For Progress Namibia project have shown a great improvement over the years, particularly Sonderwater 
where there's now access to general livelihoods and services such as clean water and sanitation. The growing interest of the community to improve existing living standards through initiatives like gardening proves the importance of small local community led initiatives. It creates an opportunity to synthesize and document similar approaches to shape development in Namibia. While the For Progress Namibia Project seems to have achieved a lot in terms of rethinking transformation at grassroots, certainly, much more needs to be done to truly transform economic thinking in the country. One of the key areas for positive change toward environmental protection in so far community development and tourism. Here, Namibia has adapted a strong community-based natural resource management approach that is promising in terms of environmental protection and the improvement of human well-being. Local communities are given the power to control and manage their resources, as a way of safeguarding the environment while improving livelihoods. This approach is promising in terms of adapting new economic thinking unlike other key areas such as mining and fisheries which have seen increases of lack of transparency and corruption. However, tourism, which carried a huge proportion of the country's employment, showed a lack of resilience during the covid pandemic when it was shown how vulnerable such a sector can be when over investment is made into high-end international supply in the tourism sector.

Corruption is a large and systemic problem, already previously spoken about in various publications, including Melber's informative book "Understanding Namibia" (Melber, 2014), but recently popularized by the uncovering of the \#fishrot saga (e.g., Aljazeera's "Anatomy of a Bribe" expose, 2019). Hope is being glimpsed now that several high officials and their family members are currently on trial due to the \#fishrot saga—and the whistle blower is receiving a sustainability award in Sweden in $2021 .^{6}$

However, public support has been garnered, and the younger generation is thinking differently about development. The fact that there has been so much volunteer support in this project, as well as overall participation, debate, and engagement, shows the deep need for further leadership.

The committee certainly made mistakes from which they have learned important lessons. But, it is important to note that transformations are uncomfortable, new, and difficult, and the more flexible and adaptive, organic, and opportunistic one can be in this movement toward a sustainable society, the more successful the eventual result will be.

There is no doubt that we are at a precipice of big change. Certainly, the solutions are there, and they are embedded in a more symbiotic, cooperative approach to human development. The most important aspect is to change perspectives and mental models about the idea of "success" and "progress" in society. The future is going the sustainability route. There is no other way. The challenge for political parties, governments, businesses, and societies in general is to shape a constructive, resilient, and creative future today, or risk being left as bystanders as events take their course.

\footnotetext{
${ }^{6} \mathrm{http}: / /$ winwingothenburgaward.com/theme-2021-anticorruption/?fbclid=IwAR0mgXXJ81_ljO HjJCJMArad-UtKcHJLRikWpFC5fvb--oVM2f54umjCGh8.
} 


\section{References}

Aljazeera. (2019). Anatomy of a bribe: a deep dive into an underworld of corruption. https://www. aljazeera.com/features/2019/12/1/anatomy-of-a-bribe-a-deep-dive-into-an-underworld-of-cor ruption.

Braby, J. (2012, August). For progress Namibia surveyor training session [Photograph]. Progress Namiba. https://www.progress-namibia.com/page/for-progress-namibia/.

Braby, J. (2016). Citizen wellbeing: Towards more appropriate measures of Namibia's success and progress. Policy Brief to Namibian politicians. https://cms.my.na/assets/documents/p1ae4q4nu 1i1ird5rij142r1s7g1.pdf.

Braby, J. (2019). What kind of a Namibia do we want? Progress Namibia Weekly (a weekly blog). https://www.progress-namibia.com/main/post/what-kind-of-namibia-do-we-want/.

Braby, J., Lavelle, J. J., Mulunga, J., Nekwaya, N., Mathias, F., \& Angula, A. (2016). Citizen wellbeing and GDP: Toward more appropriate measures of Namibia's success and progress. Journal of Social Change, 8(1), 26-38.

Braby, J., Mulunga, J., Nekwaya, N., Lavelle, J. J., Ndimbira, M. J., Mangundu, R., \& Angula, A. (2017). Towards wellbeing indicators in Africa: A case study from Namibia. Solutions Journal, 8(3). https://www.thesolutionsjournal.com/article/towards-well-indicators-africa-casestudy-namibia/.

Bromet, E., Andrade, L. H., Hwang, I., Sampson, N. A., Alonso, J., de Girolamo, G., \& Kessler, R. C. (2011). Cross-national epidemiology of DSM-IV major depressive episode. BMC Medicine, 9, 90. https://doi.org/10.1186/1741-7015-9-90

Compas, B. E., Jaser, S. S., Dunn, M. J., \& Rodriguez, E. M. (2012). Coping with chronic illness in childhood and adolescence. Annual Review of Clinical Psychology, 8, 455-480.

Constanza, R., Kubiszewski, I., Giovannini, E., Lovins, H., McGlade, J., Pickett, K. E., Ragnarsdottir, K. V., Roberts, D., De Vogli, R., \& Wilkinson, R. (2014). Development: Time to leave GDP behind. Nature, 505, 283-285.

Costanza, R., Atkins, P. W. B., Bolton, M., Cork, S., Grigg, N. J., Kassner, T., \& Kubizewski, I. (2017). Overcoming societal additions: What can we learn from individual therapies? Ecological Economics, 131, 543-550.

Fioramonti, L. (2017). Wellbeing economy: Success in a world without growth. Johannesburg: Pan Macmillan.

Hardoon, D., Ayele, S., \& Fuentes-Nieva, R. (2016). An economy for the 1\%: How privilege and power in the economy drive extreme inequality and how this can be stopped. Oxford, UK: Oxfam International. Retrieved from https://www.oxfam.org/sites/www.oxfam.org/files/file_atta chments/bp210-economy-onepercent-tax-havens-180116-en_0.pdf.

Mangundu, R., \& Braby, J. (2019). Games for sustainable development goals Namibia: Towards youth engagement in achieving sustainability. Solutions Journal, 10(3). https://www.thesoluti onsjournal.com/article/games-sustainable-development-goals-namibia-towards-youth-engage ment-achieving-sustainability/.

Mangundu, R. M. I. (2017). Professor Lorenzo Fioramonti delivers a public talk at the Namibia University of Science and Technology [Photograph]. https://www.facebook.com/ProgressNami bia/photos/843127819196563.

Mangundu, R. M. I. (2018). Processes of the pallet project [Photograph]. https://www.facebook. com/ProgressNamibia/photos/?ref=page_internal.

Mangundu, R. M. I. (2020, November). One of the project partners setting up a new backyard garden [Photograph]. https://www.facebook.com/photo.php?fbid=2297386463726300\&set=pb. 100003649061342.-2207520000.\&type $=3$.

Mebratu, D., Swilling M. (Eds.). (2020). Transformational infrastructure for development of a wellbeing economy in Africa. African Sun Media.

Melber, H. (2014). Understanding Namibia. Hurst Publishers.

Menees, J. (2014). Mental environmentalism: The true goal of the occupy wall street movement. Senior Theses. 24. https://scholarcommons.sc.edu/senior_theses/24. 
Namibia Statistics Agency. (2011). Census. Government of Namibia.

Republic of Namibiaa. (2004). Vision 2030: Policy Framework for long-term national development. Windhoek, Namibia: Author. Retrieved from http://www.met.gov.na/Documents/Vision\% 202030.pdf.

Rockström, J., Steffen, W., Noone, K., Persson, Å., Chapin, F. S. III, Lambin, E., \& Foley. J. (2009). Planetary boundaries: Exploring the safe operating space for humanity. Ecology and Society, 14(2), 32.

Rogers, D. S., Duraiappah, A. K., Antons, D. C., Munoz, P., Bai, X., Fragkias, M., \& Gutscher, H. (2012). A vision for human well-being: Transition to social sustainability. Environmental Sustainability, 4, 1-13.

Sanzila, G. (2016, February 29). Justine presents on the For Progress Namibia survey for the Parliamentary Standing Committee on Gender Equality, Social Development and Family Affairs [Photograph]. Progress Namibia. https://www.progress-namibia.com/page/for-progressnamibia/.

Steffen, W., Richardson, K., Rockström, J., Cornell, S. E., Fetzer, I., Bennett, E. M., Biggs, R., Carpenter, S. R., de Vries, W., de Wit, C. A., Folke, C., Gerten, D., Heinke, J., Mace, G. M., Persson L. M., Ramanathan, V., Reyers, B., Sörlin, S. (2015, February 15). Sustainability. Planetary boundaries: Guiding human development on a changing planet. Science, 347(6223), 1259855. https://doi.org/10.1126/science.1259855. Epub 2015 Jan 15. PMID: 25592418.

Stiglits, J., Sen, A., \& Fitoussi J. P. (2009). Report by the Commission on the measurement of economic performance and social progress. Retrieved from http://www.communityindicators. net/system/publication_pdfs/9/original/Stiglitz_Sen_Fitouss i_2009.pdf?1323961027.

Streib, L. (2007). World's fattest countries. Forbes. Retrieved from http://www.forbes.com/2007/ 02/07/worlds-fattest-countries-forbeslife-cx_1s_0208worldfat.html

Van Schalkwyk, L. (2016). Elder from Sonderwater community prioritizing land rights [Photograph]. https://www.facebook.com/ProgressNamibia/photos/a.681665728676107/681667302 009283.

Van Schalkwyk, L. (2016). Residents of Katutura-East Constituency partaking in an envisioning exercise [Photograph]. https://www.facebook.com/ProgressNamibia/photos/674968879345792

Whitby, A., Seaford, C., Berry, C., \& BRAINPOoL Consortium Partners. (2014, March 31). BRAINPOoL Project final report: Beyond GDP: From measurement to politics and policy. BRAINPOoL Deliverable 5.2, A collaborative programme funded by the European Union's Seventh Programme for research, technological development and demonstration under Grant Agreement No. 283024. World Future Council. Retrieved from http://www.brainpoolproject.eu/wp-content/ uploads/2014/05/BRAINPOoL-Project-FinalReport.pdf.

Open Access This chapter is licensed under the terms of the Creative Commons Attribution 4.0 International License (http://creativecommons.org/licenses/by/4.0/), which permits use, sharing, adaptation, distribution and reproduction in any medium or format, as long as you give appropriate credit to the original author(s) and the source, provide a link to the Creative Commons license and indicate if changes were made.

The images or other third party material in this chapter are included in the chapter's Creative Commons license, unless indicated otherwise in a credit line to the material. If material is not included in the chapter's Creative Commons license and your intended use is not permitted by statutory regulation or exceeds the permitted use, you will need to obtain permission directly from the copyright holder. 